\title{
AdvaNCED SKILls MAPPING AND CAREER DEVELOPMENT USING AI
}

\begin{abstract}
Yew Kee Wong
School of Information Engineering, HuangHuai University, Henan, China

ABSTRACT

Artificial intelligence has been an eye-popping word that is impacting every industry in the world. With the rise of such advanced technology, there will be always a question regarding its impact on our social life, environment and economy thus impacting all efforts exerted towards continuous development. From the definition, the welfare of human beings is the core of continuous development. Continuous development is useful only when ordinary people's lives are improved whether in health, education, employment, environment, equality or justice. Securing decent jobs is a key enabler to promote the components of continuous development, economic growth, social welfare and environmental sustainability. The human resources are the precious resource for nations. The high unemployment and underemployment rates especially in youth is a great threat affecting the continuous economic development of many countries and is influenced by investment in education, and quality of living.
\end{abstract}

\section{KEYWORDS}

Artificial Intelligence, Human Resources, Conceptual Blueprint, Continuous Development, Learning and Employability Blueprint

\section{INTRODUCTION}

Continuous development is defined as the development that meets the needs of the present without compromising the ability of future generations to meet their own needs [1]. The primary cause of the high unemployment rates is the inefficient education systems that fail to equip young people with the required skills for the labour market. In this research, we propose the use of artificial intelligence to enhance the relationship between education and employment.

Many studies were published on how to improve education curricula to enhance the employability of students; frameworks were designed to facilitate the work of teachers, mentors, career advisers and faculty to guide students through their career exploration and preparation. Numerous papers were published on the impact of artificial intelligence (AI) on education and its impact on employment. However it seems there is a gap in connecting the three important areas of research, 1: education for employment, 2: AI in education and, 3: AI in employment [2]. Further investigations are needed to evaluate and assess how AI can fit in the current learning and employability blueprint and to evaluate what can innovation and entrepreneurship bring to promote better education for employment systems. 


\section{USING AI TO BUILD A CONCEPTUAL BLUEPRINT}

The study is assessing new blueprint for learning and employability and how AI can fit in andfoster the process, so further experiments should be carried out to ensure the effectiveness of theblueprint and the accuracy of results of the AI application on the learning and employabilityprocess [3]. After reviewing literature regarding the impact of AI and its potential on botheducation and employment, as well as reviewing different education for employment blueprints,theories and case studies, this paper attempts to close the gap in the research related to specificscope which is the impact of AI on education for employment [4].

Young people can't find jobs. Yet employers can't find people with required skill set. This mismatch between the supply demand in the labour market might witness a bigger gap in the future with the growth of AI technologies. There are few frameworks for education for employment or in other words "Learning and Employability" [5]. However the existing model didn't address the potential of AI whether in terms of deployment of such technology within the model or in terms of the implications of AI on the learning models or the employment models. So there is a need to find a practical frame for learning and employability that incorporate the advancements of AI to facilitate the university to work transition. This paper seeks to figure out the room for AI potentials through mapping innovative startups that embraced AI capabilities to play a role in the education for employment ecosystem.

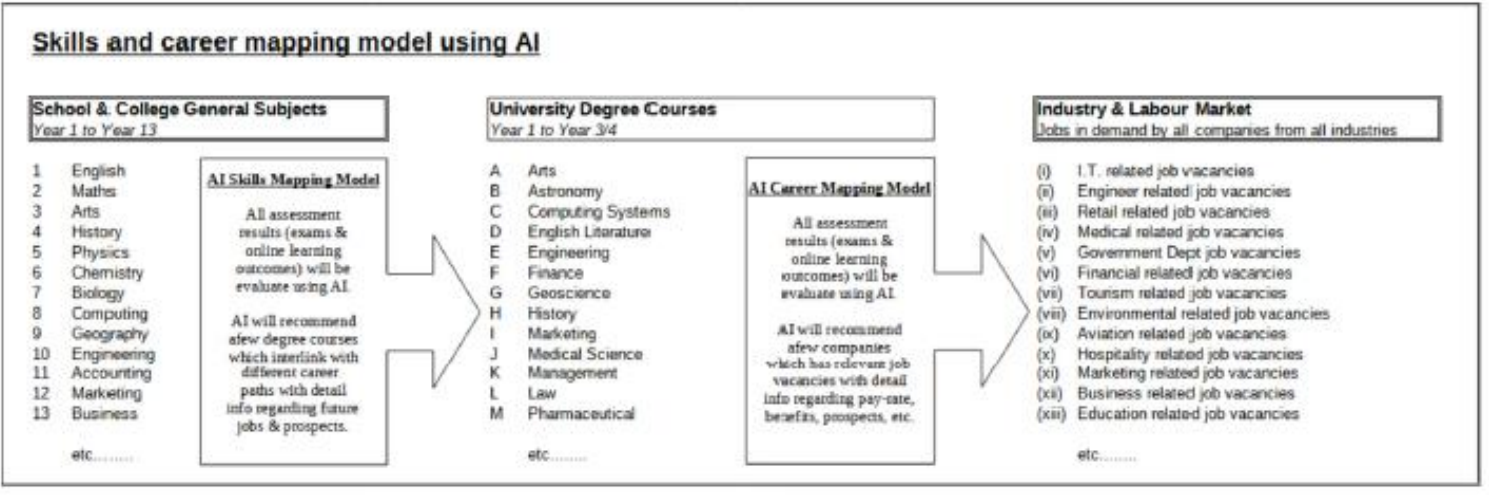

Figure 1. Skills and career mapping model using AI.

\subsection{The Use of AI in Skills Mapping Model}

In this model, we proposed to use AI to streamline the skills requires by various degrees courses. This process significantly reduce the time for the student to decide on what degree subjects they can register for the university entrance. Furthermore, the model can also assist the student by presenting the detail information regarding the different career paths, current employers that are offering job related vacancies, pay-rate range, related benefits and other prospects [6].

Some students may not have a clear career path after they completed their college study and require further guidance and advise on choosing the appropriate degree course for their future career development [7]. In this evaluation process, the AI will use all the information (i.e. exam grades/marks, understanding level from online learning, etc..) provided by the student, Therefore, AI in this process can only provide advanced in-depth career roadmaps as recommendation for the student. The final decision making still rely on the student. 


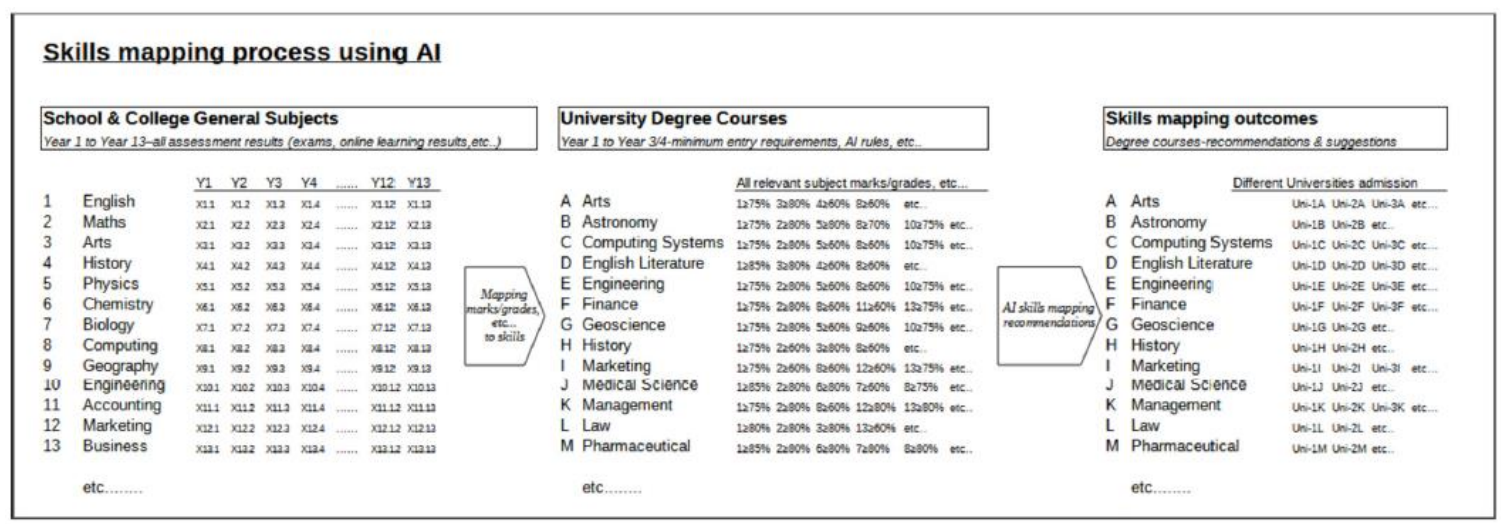

Figure 2. Skills mapping processing using AI

\subsection{The Use of AI in Career Mapping Model}

With such employment concern, many studies refined such concern and the general consensus now is that AI will generate major transformations in the labour market [8]. According to many researchers, AI will create 2.3 million jobs in 2020, while eliminating 1.8 million and by $2025 \mathrm{AI}$ related job creation will reach two million net-new jobs. Moreover, according to a new report from the World Economic Forum (WEF); 75 million jobs are estimated to be displaced, while 133 million new roles may emerge due to machines and algorithms[9]. The study has argued that this transition to technology should result in favourable unemployment that will allow human labour to better perform activities they were never able to do in their current heavy duty jobs. AI programs will probably be utilized for applications where hiring humans would be too expensive or really dangerous.

AI programs will take over computer tasks allowing humans to dedicate their time to other kinds of tasks including personal services. Service sector companies are optimistic about big data and enthusiastic about AI and robotics deployment as it will have direct impact on productivity improvement that eventually reflects on economic growth. On the other hand, it was realized that AI canpositively impact employment if it is utilized properly within the business model [10]. AI uses in creating effective recruitment systems is seen as an inevitable opportunity to make best use of it. Still this will stay challenging until firms management pay attention to the importance of allocating budgets to finance the required technology for hiring process.

Once the students graduated from the University, they can directly enter the labour market with the help from AI career managing model. The model will provide recommendations and information related to jobs. So that to the graduates can prepare for interviews and other job application process, such as IQ \& EQ tests, body check etc. This process can significantly reduce the amount of time graduates need to search for jobs, interviews and other tedious job searching steps and at the same time also reduce the amount of time the employer can recruit the appropriate personnel to fulfil the position and task required in the company, hence can indirectly improve the productivity rate of the company. 


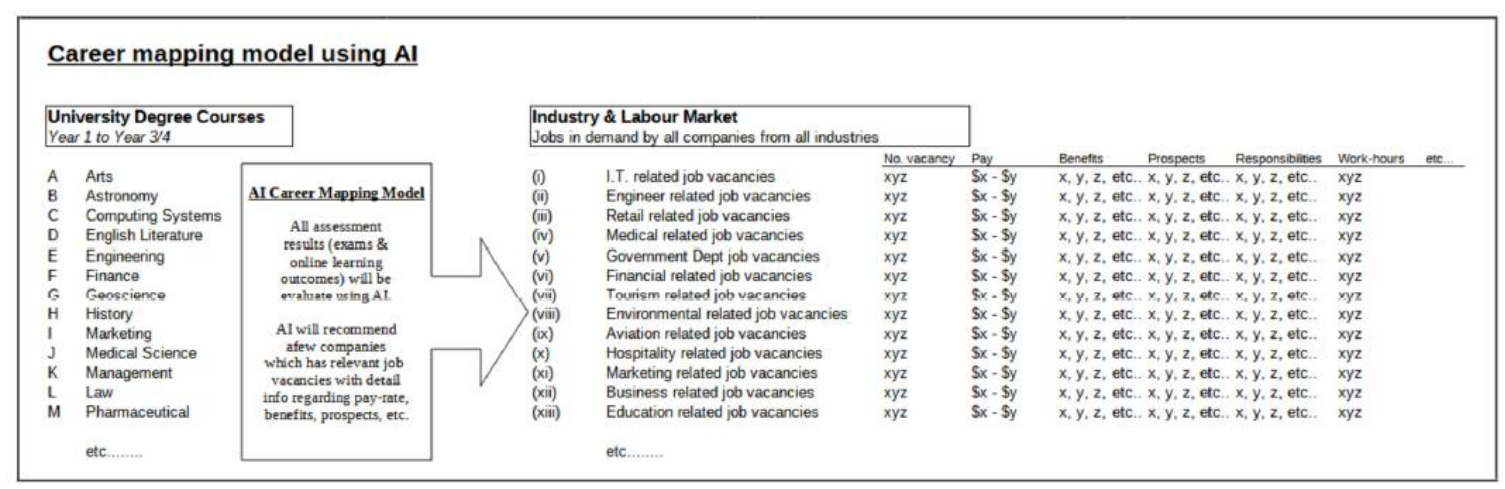

Figure 3. Career mapping processing using AI.

\section{LEARNING AND EMPLOYABILITY BLUEPRINT}

Aside from the impact of AI in creating new jobs, replacing jobs or even shift in the job and labour market, there are two global employment crises that already exist away from the implications of AI; high levels of youth unemployment and a shortage of talents who possess critical job skills. Mourshed, Farell, \& Barton [11] argued that if young people graduating from schools and universities, after exerting lots of efforts, cannot secure decent jobs and observe that sense of respect that comes with such degrees, society may witness outbreaks of anger or even violence. There is an information gap in what works and what does not in preparing young people during their school to employment transition. I summarized this information gap and it clearly shows there is a clear disconnect and misperception about youth job readiness from the point of view of employers vs youth vs educational institutions.

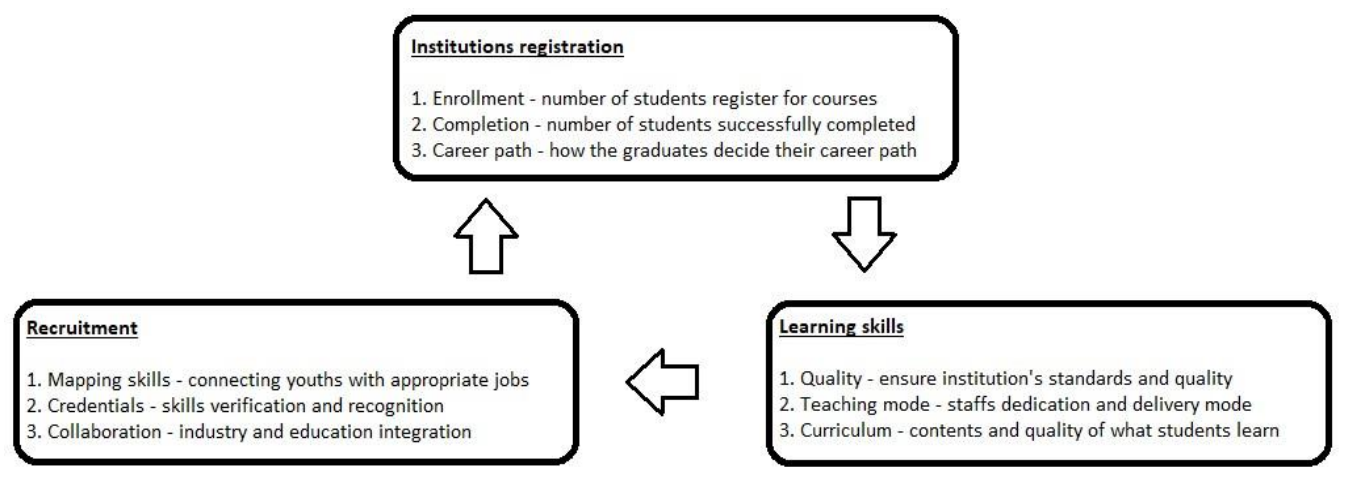

Figure 4. Blueprint for exploring the education to employment system.

\subsection{Institutions Registration}

\section{A. Information Sharing}

All institutions are recommended to develop a comprehensive occupations database and educational/training opportunities and provide information, advice and guidance to help job seekers to make decisions on learning, training and work. The comprehensive occupation database and website allows users to explore different career options including jobs profile, salaries, industry trends and offer webchats with career advisors beside their skills health check assessment that help users to find out what kind of jobs that best suits his/her skills. Users can also find training opportunities. 


\section{B. Dealing with Social Perception}

It seems that a perception is widespread that getting a decent job with good salary requires being a college graduate. So this puts social pressure on youth to go to college and influence others' choice away from the vocational tracks [12]. Brunello and Rocco [13] argued that youth who graduated from vocational education have a higher likelihood of being not employed and with no education or training within the past 12 months. They also found that vocational education is associated with poorer labour market returns. This as a result impacted on the perception about vocational education.

\section{Dealing with Education Affordability}

Schultz [14] and Becker [15] introduced individual choice model of human capital investment in which they presented individual's education choice as an investment decision. Individuals sacrifice economically in order to acquire knowledge, referred to as 'human capital', that will enable them to get better rewards in the future. If young people have no access to credit or savings, this may limit their choices and they will not be able to enrol in study.

\subsection{Learning Skills}

\section{A. Effective Content and Curriculum Design}

Mourshed et al. [11] proposed that in order to design relevant curriculum to the employers' requirements, close engagement between, industry leaders and educational providers is needed. Such engagement to succeed, intensive collaboration should exist while defining the core requirements on a very detailed level to ensure that the aspired learning outcomes will be achieved.

\section{B. Effective Delivery Methods}

Effective delivery requires still close engagement between employers and educational providers. Mourshed et al. [11] explored two main ways to do so - (1): Classrooms within workplaces. The common model to bring vocational and technical training within the workplaces is through internships or apprenticeships. (2): Workplaces within classrooms. Internships and apprenticeships are types of hands-on learning experiences that are most admired by students, however the number of opportunities are limited to accommodate certain capacities of students.

\subsection{Recruitment}

\section{A. Assessment for Qualifications and Certifications}

Finding a job is a painful process for job seekers. Job seekers strive to market their skills, but can't find a credible way to prove their talents, and Employers can't trust the educational degree as a main reference validating youth skills and knowledge. So both employers and candidates suffer in the hiring and talent acquisition process. One of the well known processes to show one's credentials and prove his skills and knowledge in a credible way is the international professional certifications such as PMP (Project Management Professional) or CPA (Certified Public Accountant) which could be obtained by Individuals after passing standardized tests. Another innovative solution for the assessment and credentials that crossed countries boundaries is the digital badges which introduce much entertainment for online educational activities and experiences. 


\section{B. Match Making}

Based on their survey that covered more than 100 initiatives in 25 countries, Mourshed et al. [11] observed that there are many cases that educational providers have built strong relationships with employers so that they can hire their graduates immediately after graduation based on the matchmaking and recommendation process that is being done by the educational providers themselves. With current technological advancement, matchmaking could be a game changer in the employment scene.

Flanagan [16] also agreed that Tinder-style matchmaking is beneficial in the job market as well and shed the light on a similar app called "Emjoyment" which allow job seekers to swipe job posts which includes major highlights about the company, location and only one sentence job description and once the job seeker find a good post, he just hits "like". On the other side, employers start to see job seekers who liked their opportunity in a form of cards including resumes main highlights and if the recruiter found an interesting profile, he also hits "like" and at that moment both parties connect together at a push of a button. This kind of matchmaking innovations could decrease the time lost in job applications and finding a good candidate and create direct engagement between employers and job seekers.

\section{Artificial InTElligence System}

The conceptual blueprint using artificial intelligence system include several components which can be integrated as one complete artificial intelligence system [17]. These are the standard components [18]:-

- Reasoning - It is the set of processes that empowers us to provide basis for judgement, making decisions, and prediction.

- Learning - It is the activity of gaining information or skill by studying, practising, being educated, or experiencing something. Learning improves the awareness of the subjects of the study.

- Problem Solving - It is the procedure in which one perceives and tries to arrive at a desired solution from a current situation by taking some path, which is obstructed by known or unknown hurdles.

- Perception - It is the way of acquiring, interpreting, selecting, and organizing sensory information.

- Linguistic Intelligence - It is one's ability to use, comprehend, talk, and compose the verbal and written language. It is significant in interpersonal communication.

The potential of online learning system include 4 factors of accessibility, flexibility, interactivity, and collaboration of online learning afforded by the technology. In terms of the challenges to online learning, 6 are identified: defining online learning; proposing a new legacy of epistemology-social constructivism for all; quality assurance and standards; commitment versus innovation; copyright and intellectual property; and personal learning in social constructivism. 


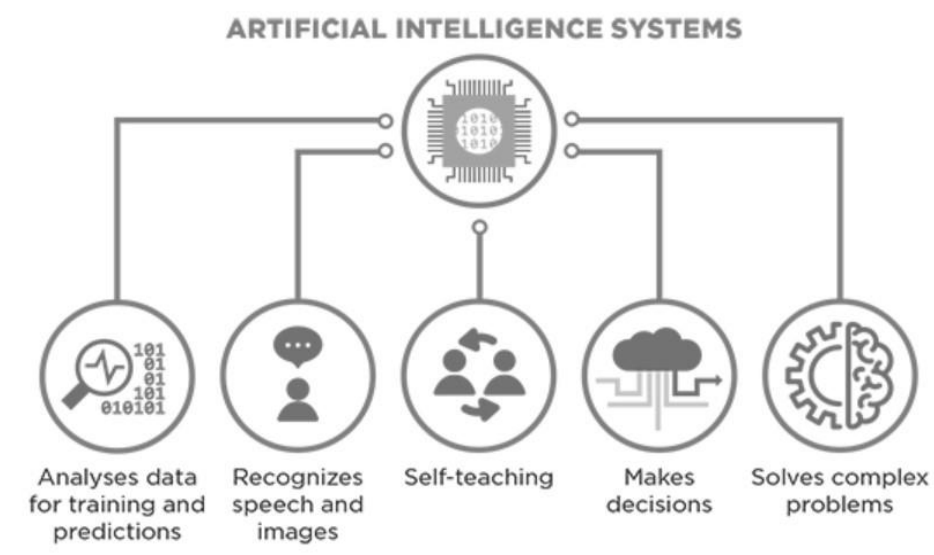

Figure 5. The artificial intelligence online learning system components.

\section{Conclusions}

This research was proposed by understanding the inter-relation between education and employment, what blueprints and systems that worked, and how AI can impact in the education for employment process whether by introducing new innovations that foster students learning process and placement in the job market or by harming the process and introducing unintentional bias, privacy breach, escalating power consumption and replacing human in workplaces. This paper is assessing new blueprints for learning and employability and how AI can fit in and foster the process, so further studies and experiments should be carried out to ensure the effectiveness of the blueprint and the accuracy of results of the AI application on the learning and employability process.

\section{REFERENCES}

[1] World Commission on Environment and Development (1987). Our Common Future. Oslo.

[2] Tuomi, I. (2018). The Impact of Artificial Intelligence on Learning, Teaching, and Education. Publications Office of the European Union.

[3] Popenici, S., \& Kerr, S. (2017). Exploring the impact of artificial intelligence on teaching and learning in higher education. Research and Practice in Technology Enhanced Learning.

[4] Bayne, S. (2015). Teacherbot: interventions in automated teaching. Teaching in Higher Education, 455-467.

[5] Schmidt, A. (2017). How AI Impacts Education. Retrieved February 2019, from Forbes:https://www.forbes.com/sites/theyec/2017/12/27/how-ai-impactseducation/\#22edd83f792e.

[6] Hawksworth, J. (2018). AI and robots could create as many jobs as they displace. Retrieved 2019, from World Economic Forum: https://www.weforum.org/agenda/2018/09/ai-and-robots-could-create-as-many-jobs-as-theydisplace/.

[7] Andrews, W. (2018). Craft an Artificial Intelligence Strategy: A Gartner Trend Insight Report. Gartner, Inc.

[8] Khakurel, J., Penzenstadler, B., Porras, J., Knutas, A., \& Zhang, W. (2018). The Rise of Artificial Intelligence under the Lens of Sustainability. Technologies , 6(4), 100.

[9] The Future of Jobs (2018). Centre for the New Economy and Society.

[10] Martens, B., \&Tolan, S. (2018). Will this time be different? A review of the literature on the Impact of Artificial Intelligence on Employment, Incomes and Growth. Digital Economy Working Paper 2018-08; JRC Technical Reports.

[11] Mourshed, M., Farrell, D., \& Barton, D. (2019). Education to employment: Designing a system that works. Retrieved April 1, 2019, from McKinsey Center for Government: https://www.mckinsey.com/industries/social-sector/our-insights/education-to-employmentdesigninga-system-that-works. 
[12] Boyer, R. H., Peterson, N. D., Arora, P., \& Caldwell, K., (2016). Five Approaches to Social Sustainability and an Integrated Way Forward. Sustainability, 8(9), MDPI AG.

[13] Brunello, G., \& Rocco, L. (2017). The effects of vocational education on adult skills, employment and wages: What can we learn from PIAAC? Springer Link, 8-315.

[14] Schultz, T. W. (1961). Investment in Human Capital. The American Economic Review , 1-17.

[15] Becker, G. S. (1962). Investment in Human Capital: A Theoretical Analysis. Journal of Political Economy, 9-49.

[16] Flanagan, J. (2014). Tinder-style matchmaking helps you bag your next job. Retrieved from New Scientists: https://www.newscientist.com/article/dn25172-tinder-style-matchmakinghelps-you-bagyour-next-job/.

[17] Gus Bekdash, (2019). Using Human History, Psychology, and Biology to Make AI Safe for Humans, Chapman \& Hall/CRC.

[18] The Student Circles.com, Artificial Intelligence Study Notes https://www.thestudentcircle.com/quickguide.php?url=artificial-intelligence

\section{AUTHOR}

Prof. Yew Kee Wong (Eric) is a Professor of Artificial Intelligence (AI) \& Advanced Learning Technology at the HuangHuai University in Henan, China. He obtained his BSc (Hons) undergraduate degree in Computing Systems and a Ph.D. in AI from The Nottingham Trent University in Nottingham, U.K. He was the Senior Programme Director at The University of Hong Kong (HKU) from 2001 to 2016. Prior to joining the education sector, he has worked in international technology companies, HewlettPackard (HP) and Unisys as an AI consultant. His research interests include AI, online learning, big data analytics, machine learning, Internet of Things (IOT) and blockchain technology.

(C) 2021 By AIRCC Publishing Corporation. This article is published under the Creative Commons Attribution (CC BY) license. 